\title{
A novel approach to frequency support in a wind integrated power system
} \author{
Haile-Selassie Rajamani ${ }^{\mathrm{d}}$ \\ ${ }^{a}$ Department of Avionics, Indian Institute of Space Science and Technology, Thiruvananthapuram 695 547, India \\ ${ }^{\mathrm{b}}$ School of Electronic, Electrical and Systems Engineering, Loughborough University, United Kingdom \\ ${ }^{c}$ School of Electrical and Electronics Engineering, Newcastle University, United Kingdom \\ ${ }^{\mathrm{d}}$ School of Electrical Engineering and Computer Science, University of Bradford, United Kingdom
}

M. Deepak ${ }^{\mathrm{a}}$, Rajesh Joseph Abraham ${ }^{\mathrm{a},{ }^{*}}$, Francisco M. Gonzalez-Longatt ${ }^{\mathrm{b}}$, David M. Greenwood ${ }^{\mathrm{c}}$,

\section{A R T I C L E I N F O}

Article history:

Received 16 August 2016

Received in revised form 6 January

2017

Accepted 19 February 2017

Available online $\mathrm{xxx}$

Keywords:

Flywheel energy storage (FES)

Particle swarm optimization (PSO)

Thyristor controlled series compensator (TCSC)

Wind penetration

\section{A B S T R A C T}

This paper discusses the impact of wind penetration on frequency control of a thermal dominated system considering Generation Rate Constraints (GRC) and dead band non-linearities. The hidden inertia emulation and coordinated operation of conventional power generation systems with wind energy can effectively alleviate the frequency excursions during sudden load disturbances. Conventional energy storage device like Flywheel Energy Storage (FES) system can be used in conjunction with wind integrated power system to overcome the intermittent nature of power generation. Thyristor Controlled Series Compensator (TCSC) is found to be effective in damping low frequency oscillations in weak tie-lines and supplement the frequency regulation. A stochastic population based evolutionary computation technique - Particle Swarm Optimization (PSO) is used to tune the controller gains. A strategy comprising inertia control, coordinated operation of conventional generation units with wind energy and TCSC-FES has been proposed to enhance the frequency regulation which is effective in controlling low frequency oscillations as established by the simulation results.

(C) 2016 Published by Elsevier Ltd.

\section{Nomenclature}

$f$

$P_{r i}$

$H$

$\Delta P_{D i}$

$\Delta P_{G i}$

$T_{12}$

$R_{i}$

$T_{G i}$

$T_{R i}$

$T_{T i}$

$B_{i}$

$K_{R i}$

$\mathrm{J}$

$T_{T C S C}$

$K_{\text {TCSC }}$

$T_{\text {FES }}$

$K_{F E S}$

$K_{I i}$

$T_{w}$

$T_{R}$

$T_{A}$

$T_{c}$

$K_{P}$

\footnotetext{
* Corresponding author.

Email address: rajeshja@gmail.com (R.J. Abraham)
}

$K_{I}$

Integral gain constant of the speed recovery loop

\section{Introduction}

Power generation using renewable energy sources such as solar, wind, biomass, geothermal etc. has gained momentum among electric power utilities owing to increase in electric energy demands, fast depleting sources of fossil fuels and considerations for environmental concerns such as emission of carbon dioxide and other green house gases. Currently, wind energy penetration has gone up significantly with variable speed type wind turbines. Thus conventional sources are getting replaced by Doubly Fed Induction Generator (DFIG) type wind turbine as the penetration level increases [1-3]. In a traditional power system, conventional sources like hydro, thermal etc. are the main sources of inertia that is stored in the form of kinetic energy in the rotor. However, the inertia provided by the DFIG type wind turbine is negligibly small because the rotor is decoupled from the grid through power electronic interface. With decreasing levels of inertia, an increased frequency excursion is observed after a sudden load perturbation which is of concern for plant operators as well as turbine manufacturers. Plenty of research works that are concerned with frequency support using variable speed wind turbines are available in the literature based on (a) inertia control [2-15] (b) speed recovery [6,7] and (c) coordinated operation with neighbouring conventional sources $[7,8]$.

In inertia control, the stored kinetic energy in the rotor mass of wind turbine is fed back to the grid when a sudden load demand occurs. This fast acting energy reserve can be delivered only for a short 
period [4]. Inertia control is normally activated when load change occurs. This is done by adding a control loop for enhancing the inertia support from DFIG wind turbine [16]. A method to emulate inertia to support primary frequency control has been presented in Ref. [9]. This involves releasing kinetic energy stored in the rotating mass of the turbine. Coordinated inertial control, rotor speed control and pitch angle control have been presented in Ref. [5] for regulating frequency with DFIG wind turbines under various wind conditions. Normally modern wind turbines such as GE 1.5 MW wind turbines are equipped with inertial control, which emulates the inertia of wind turbines and support during transients [17-19]. A control strategy for variable speed wind turbines to participate in primary frequency control has been proposed in Ref. [20]. It deploys the stored kinetic energy in the rotating masses to reduce the need of deloaded operation. A modified control that introduces inertia response to the DFIG wind turbine with high-voltage dc interconnection to alter the frequency behavior has been proposed in Ref. [21]. The study in Ref. [11] has developed a control strategy to mitigate the impact of reduced inertia in high wind penetrated system. The proposed scheme deals with reintroducing inertia using power electronics converter and pitch angle adjustment, to provide improved inertia response during grid frequency excursion. The use of wind turbines in primary frequency control considering transient and droop characteristics has been discussed in Ref. [22] while [23] has presented a load frequency control design using Model Predictive Control (MPC) technique in a multi-area power system with wind turbines. The authors of [24] have suggested two main de-loading techniques: over-speeding and pitch controlled de-loading of wind generators which could enable wind generators to participate in load frequency control. To behave like a conventional synchronous machine, a supplementary control with variable droop has been introduced to deloaded turbines during depressed frequency [25]. As shown in recent works $[6,8,9,16,26]$, additional schemes can be implemented to give the turbines a virtual/synthetic inertia.

Most of the proposed solutions available for frequency regulation with high wind integration have considered either inertial emulation, droop control or pitch angle adjustment. Deepak and Abraham [27] has proposed a maiden application of TCSC to improve load following in a deregulated power system. Similarly, various energy storage devices are also used in conjunction with renewable sources to enhance their performance [28]. Among them, Flywheel Energy storage (FES) is found to be the most efficient in storing this intermittent energy whenever available and supplying it to the grid as required [29]. Apart from stabilizing the intermittent energy sources, FES can also be used for controlling frequency and tie-line power flows [30]. Their advantages include operability at normal temperature, low losses during standby and long life time.

Primary frequency control with wind turbines in comparison with conventional system is more cumbersome. Existing methods of inertia emulation [4-17] suggest the extraction of stored kinetic energy from the wind turbine rotor in the wake of sudden load disturbances which leads to a reduction in its rotor speed. To work at a specified speed limit, a recovery system should bring back Wind Turbine Generator (WTG) rotor speed to its nominal value by absorbing energy from the grid. This results in a second frequency dip in the system that may be worse than the first one. If the WTG rotor speed is not recovered, wind turbine will not inject additional energy into the grid [31]. This will result in reduction in overall system efficiency [32]. Hence, this work emphasizes on reducing the stress in the WTG rotor by allowing it to less release energy for a short duration.

This paper aims at enhancing the primary frequency support from DFIG by incorporating inertia response, in tandem with conventional sources and coordinated operation with TCSC-FES. When a load perturbation occurs, the kinetic energy associated with the system inertia that is stored in the rotor of conventional generators will be released to the grid. Hence the rotor speed changes. However with the inclusion of WTG, the effective system inertia gets reduced which needs to be compensated for. With inertia response, the kinetic energy stored in the rotating mass of WTG rotor will be released to the grid. This results in the variation of the rotor speed which will be reset to the rated value later. Since the stored kinetic energy linked to machine inertia constant is limited and available for short duration of time, the conventional generating units should take up the extra load demand. Communication must be established between conventional sources and wind turbines so as to mitigate load imbalance as fast as possible. Meanwhile, Flywheel energy storage can effectively serve as an energy source and sink - storing energy during low load condition and dispatching the stored energy to meet the load requirement when needed. On the other hand, a TCSC can dynamically control the transmission line reactance thereby controlling the power flow transfer and hence the tie-line power flow perturbations. The TCSC-FES combination further enhances the frequency regulation by not letting the DFIG to release the entire stored energy but forcing the FES to release the already available stored energy instantaneously. Hence, combined together, FES-TCSC combination has the capability to control the dynamic characteristics of frequency regulation effectively by not letting the DFIG to release the entire stored energy but making FES to release the already available stored energy. Hence, the main contributions of this paper are as follows:

- A modelling approach enabling the simulation of dynamic frequency events in a multi-area power system with wind penetration.

- Proposal of a FES system to improve primary frequency regulation in a power system with high wind penetration.

- A combined frequency control scheme using FES, TCSC, and conventional generation.

Simulation of various wind penetration scenarios with the above have been carried out using MATLAB ${ }^{\circledR}$ R2013b. Further, the proposed scheme has been compared with one of the already existing methods [16]. Since load frequency control analysis is done for short duration of time, a constant wind speed is assumed.

The rest of the paper is organized as follows: Section II describes a simplified single area power system model and DFIG wind turbine. Wind turbine model for analysis is presented in Section 3. The system under investigation is described in Section 4 followed by a discussion of PSO technique in Section 5. Section 6 gives results and discussions. Finally, conclusions are presented in Section 7.

\section{Models for frequency regulation}

The power system model to accommodate non conventional generation for simulation studies is presented below.

\subsection{Power system model}

Fig. 1 shows a classical single area power system model for frequency regulation studies [7]. Block $\mathrm{G}$ denotes a conventional generation unit and simulates the dynamics of an equivalent machine representing a system with different kinds of generation technologies (hydro turbine, gas turbine, steam turbine, alternative engine, etc.), along with its governor. Power reference $\mathrm{U}$ is the input to block $\mathrm{G}$ and the change in generated power $\Delta P_{G}$ is the output.

The change in system active power demand $\left(\Delta P_{D}\right)$ and the change in power interchanged with neighbour systems as $\left(\Delta P_{t i e}\right)$ are 


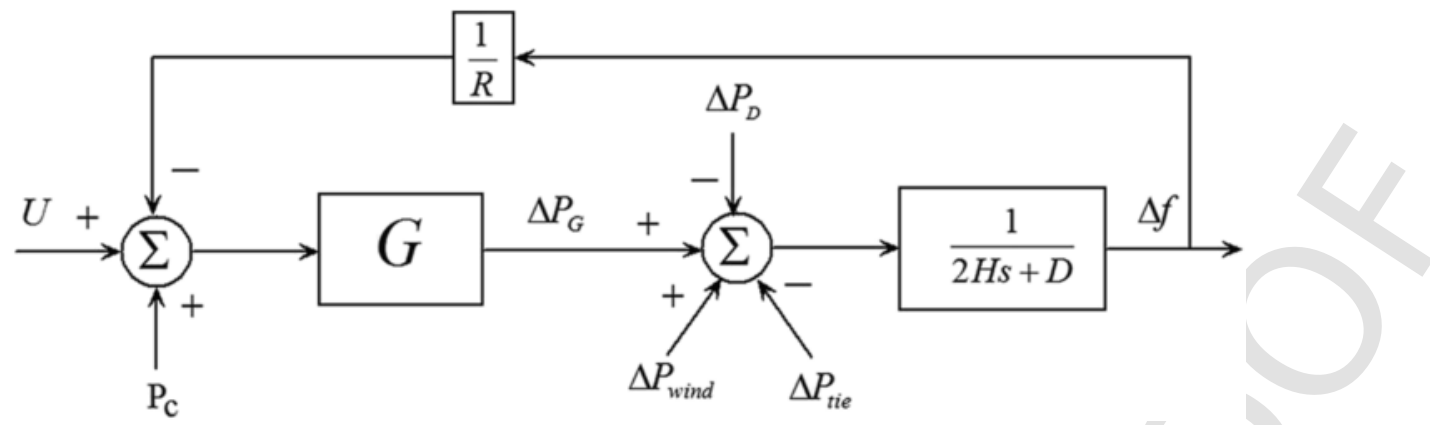

Fig. 1. Single area with non conventional generation.

subtracted from the change in generated power $\left(\Delta P_{G}\right)$. To consider thechange in power injection from wind power generation unit, a new term $\Delta \boldsymbol{P}_{\text {wind }}$ is added. At steady state, the total power balance is given as,

$$
\Delta P_{G}-\Delta P_{\text {tie }}+\Delta P_{\text {wind }}-\Delta P_{D}=0
$$

The term U stands for the secondary control or Automatic Generation Control (AGC) power reference while $P_{c}$ is a coordination signal coming from the Wind Energy Conversion System (WECS), which will make conventional generators aware of frequency support from the WECS.

\subsection{Variable speed wind turbine systems}

Fig. 2 depicts the most commonly used variable-speed machine for WECS [typical Doubly Fed Induction Generation (DFIG) unit]. Variable speed operation is commonly used in wind energy system due to their wide range of operating speeds, robust structure, less investment in power conditioning system [33], reduced inverter cost, reduced cost of the inverter filters and EMI filters, improved system efficiency and ease of power-factor control at lower cost [34]. DFIG can be considered as a conversion system that links a mechanical force (wind) through an asynchronous electrical link to the rest of the power system, as shown in Fig. 2. It can effectively control both active and reactive powers injected into the grid through the power electronics interface so that the desired operating conditions can be achieved. Optimum power extraction from the available wind is carried out using Maximum Power Point Tracking (MPPT) implemented in power electronic controllers. Various primary frequency strategies like inertia emulation, speed recovery control etc. are associated with these controllers to make DFIGs behave like a conventional generator. In this work, DFIG is assumed to work in the optimal power extraction curve thereby extracting the maximum available energy from wind.

\subsection{Wind turbine aerodynamic model}

This paper addresses the frequency regulation with variable speed wind turbines utilizing inertia control and coordinated operation of Wind Turbine (WT) and conventional generators. The maximum mechanical power that can be extracted from the wind by WT is given by Ref. [35]

$$
P_{o p t}=\frac{1}{2} \rho C_{p o p t}\left(\lambda_{o p t}, \beta\right) A U_{m}^{3}
$$

where, $C_{\text {popt }}$ is the optimal power coefficient of the wind turbine expressed as a function of tip speed ratio $(\lambda)$ and pitch angle $(\beta), A$ is the effective swept area in $\mathrm{m}^{2}, U_{m}$ is the wind speed in $\mathrm{m} / \mathrm{s}$ and $\rho$ is the air density in $\mathrm{kg} / \mathrm{m}^{3}$. The optimal power coefficient $C_{\text {popt }}$ is given by the following function [35]

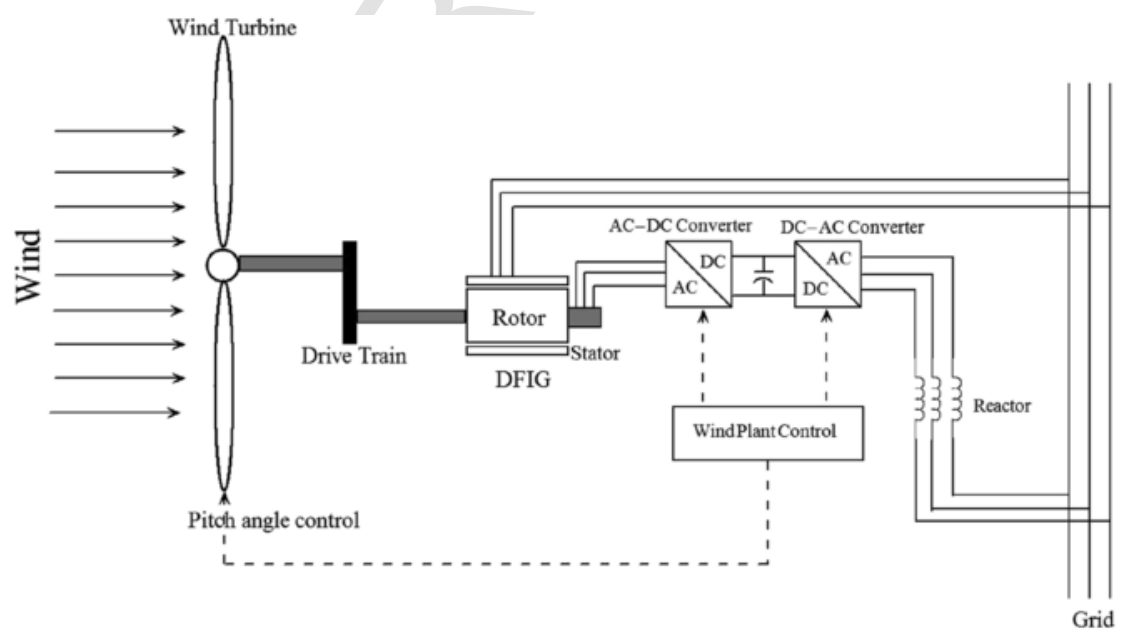

Fig. 2. Equivalent energy conversion system of DFIG. 


$$
\begin{aligned}
& C_{\text {popt }}\left(\lambda_{\text {opt }}, \beta\right)=0.22\left(\frac{116}{\lambda_{i}}-0.4 \beta-5\right) e^{\frac{-12.5}{\lambda_{i}}} \\
& \frac{1}{\lambda_{i}}=\frac{1}{\lambda_{\text {opt }}+0.08 \beta}-\frac{0.035}{\beta^{3}+1}
\end{aligned}
$$

where the optimal tip speed ratio is given as

$$
\lambda_{o p t}=\frac{\omega_{t_{o p t}} R}{U_{\omega}}
$$

$\mathrm{R}$ being the blade radius in $m$ and $\omega_{t_{\text {opt }}}$ being the optimal WT rotor speed for a given wind speed in rad/s.

\section{Schemes used for frequency regulation using wind turbines}

The proposed scheme is a combination of primary droop control with speed recovery and coordinated operation with conventional sources. Fig. 3 gives a schematic overview of the proposed model.

\section{Primary droop control}

A wind generator possesses significant amount of stored kinetic energy in the rotating mass similar to that of its conventional counterpart. Due to the power electronic interface, the rotor of the variable speed wind turbines are decoupled from the grid causing negligible contribution of inertia from WECS. This leads to reduction in overall system inertia with high wind penetration, which is the prime cause of larger frequency nadir during load disturbances. To overcome this and to emulate "hidden inertia", a droop based control strategy has been used in this paper to support primary frequency control for a short period of time (in the order of seconds) after the load perturbation.

Active power injected from WTG is proportional to the deviation in system frequency, $\left(\Delta f_{\text {sys }}=f_{\text {sys_measured }}-f_{\text {sys_nominal }}\right)$ and the pri- mary droop control is activated only when grid frequency exceeds certain limit, similar to the droop control in conventional generating units. Fig. 3 shows the primary frequency control characterized by R, with frequency deviation as the control signal. A filter is used in this loop to remove the steady state frequency error. The power injected is given follows;

$$
\Delta P_{f}^{\prime}=\frac{-1}{R} \Delta f_{m}^{\prime}
$$

where, $\Delta P_{f}^{\prime}$ is the signal given to power electronics controllers, which effectively releases the stored kinetic energy and $\Delta f_{m}^{\prime}$ is the filter frequency deviation.

\section{Speed recovery}

Due to sudden release of the stored kinetic energy from the WTG rotor, the primary droop control gets activated resulting in reduction of the rotor speed. To bring the WTG rotor speed back to its optimal rated value, a Proportional Integral (PI) controller is activated soon after the occurrence of load disturbance. This speed recovery loop absorbs energy from the grid when the frequency deviation settles down to zero and is relatively slow in comparison with primary droop control. This avoids a negative impact on WECS performance.

\section{Coordination with conventional sources}

A sudden load perturbation results in frequency changes which activates the primary droop control. This ensures the contribution of extra kinetic energy to the grid to avoid the large frequency nadir. Due to this, conventional generators doesn't take up the excess load, resulting in reduction of WTG rotor speed, which may force the WTG to move out from the grid. To avoid this, communication signals are given to conventional generators to take up this extra load demand. It should be noted that

$$
\sum_{i=1}^{n} K_{c i}=1
$$

\section{Primary droop control}

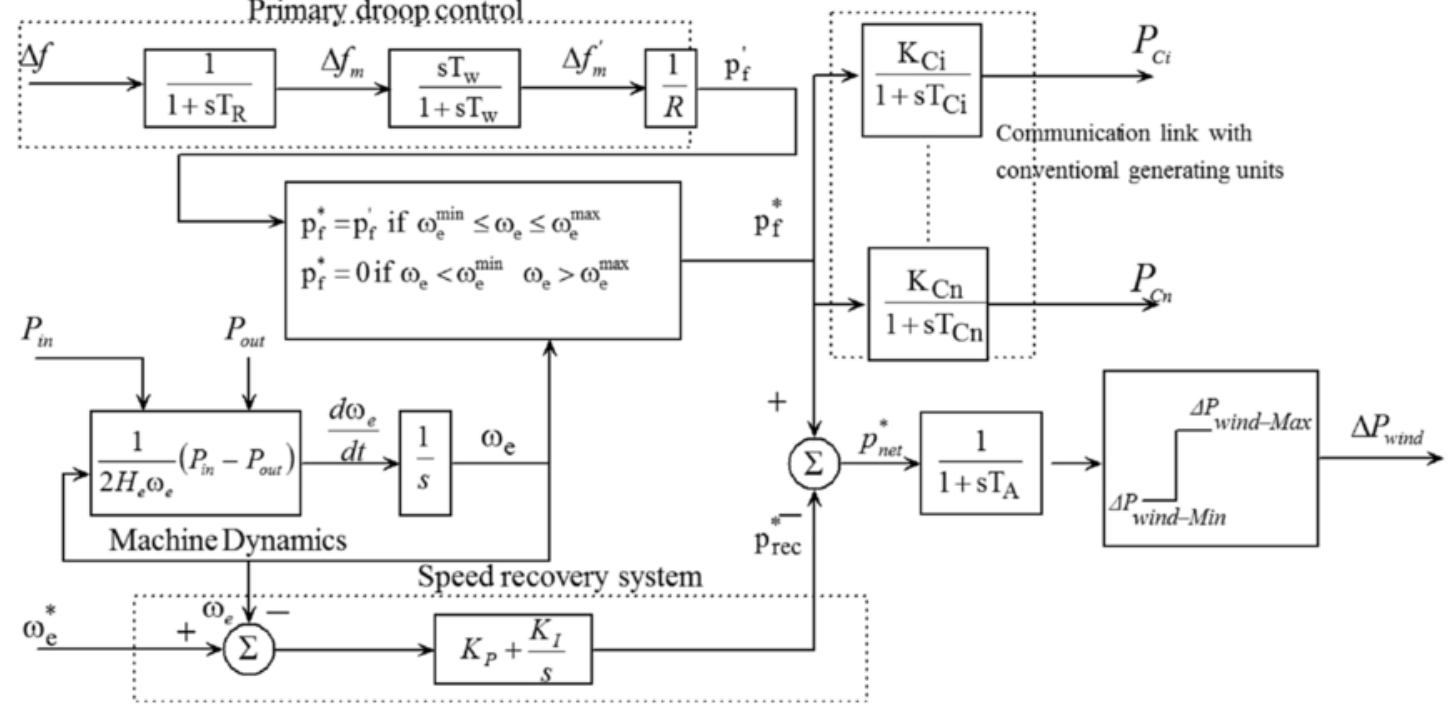

Fig. 3. Proposed control strategy and WECS model $[7,36]$. 
where, $K_{C i}$ is the gain of $i^{\text {th }}$ communication link. Thus coordination between conventional and WECS helps in reducing the negative impact of primary droop control. The power output of the WTG is limited to a range of $0-1.2 \mathrm{pu}$. Modern power systems are designed to supply power on demand with high reliability. For the satisfactory operation of power, system frequency and voltage should be kept fairly constant.

\subsection{Linearized model of TCSC}

By changing its reactance, a Thyristor Controlled Series Compensator (TCSC) can continuously change the transmission line impedance to which it is connected. TCSC is considered as a variable reactance, the value of which is adjusted automatically to constrain the power flow across the branch to a specified value. The variable reactance $X_{T C S C}$ represents the net equivalent reactance of the TCSC, when operating in either the inductive or the capacitive mode.

Considering TCSC in series with the tie-line and near to area-1, Fig. 4 shows the schematic diagram of a sample two area interconnected thermal dominated power system with wind penetration. Generally the reactance to resistance ratio of the tie-line is quite high $(\mathrm{X} / \mathrm{R} \gg 10)$ so that, while modelling the power system, the effects of tie-line resistance can be neglected.

The deviation in the tie-line power flow with TCSC after the perturbation becomes [27],

$$
\begin{aligned}
\Delta P_{t i e 12}= & \frac{2 \pi T_{12}^{0}}{s\left(1-k_{c}^{0}\right)}\left[\Delta f_{1}(s)-\Delta f_{2}(s)\right] \\
& +\left[\frac{J_{12}^{0}}{\left(1-k_{c}^{0}\right)^{2}}\right] \frac{K_{T C S C}}{1+s T_{T C S C}} \Delta f_{1}(s)
\end{aligned}
$$

The equivalent representation of TCSC corresponding to Eqn. (8) is shown in Fig. 5. It is evident that a TCSC in series with tie line can effectively vary the tie-line reactance, thereby changing the net power flow through the line. Hence by suitably adjusting the TCSC compensation, tie line power flow perturbations can be controlled which in turn controls the frequency perturbations. Thus, TCSC can damp out the low frequency oscillations in tie-line power flow and area frequencies which in turn helps to achieve better frequency regulation in system (see Fig. 6).

\subsection{Flywheel energy storage (FES)}

An FES system mainly comprises a Flywheel (rotor), motor/generator, power conversion system and magnetic bearings [28]. Fly- wheel is a mechanical battery that stores energy in the form kinetic energy. FES takes electrical energy as the input to accelerate the rotor and stores it in the form of mechanical energy. When required, this stored energy is converted to electrical energy by using the same motor/generator [37]. Permanent magnetic motors dispense higher energy density due to higher magnetic flux as compared to an induction motor. Reduction of mechanical and aerodynamic friction can be achieved by using magnetic bearings and by operating the flywheel in vacuum [28]. The amount of stored energy is high in the case of a flywheel having lower mass density and higher tensile strength. Stored energy in FES is given by $E=\frac{1}{2} I w^{2}$, where I is the moment of inertia and $\omega$ is the angular velocity. For a fixed shape flywheel, moment of inertia is constant and hence, angular velocity is the only measure of stored energy.

The small signal model of FES can be represented as a first order model by considering the change of stored energy $Q$ in an energy storage device equal to the difference between the grid power $P_{G}$ and load demand $P_{D}$ multiplied by efficiency. A simple model of the flywheel system given by Ref. [37]

$$
\frac{\mathbb{d} Q_{f w}}{\mathbb{d} t}=\left(P_{G}-P_{D}\right) f-\frac{1}{T_{f w}} Q_{f w}
$$

where, $T_{f w}=\frac{I_{f w}}{2 B_{\text {loss }}}$. The above equation gives a first-order approximation of flywheel system with load demand $P_{D}$ and grid power $P_{G}$. The energy stored in the flywheel acts as a buffer between the grid and the load [37]. The economic benefits of using FES in conjunction with wind power plants in frequency control, load leveling etc have been reported in literature $[30,38,39]$.

\section{System configuration}

Fig. 7 shows a sample AGC system on which investigations have been carried out. The system comprises a two area thermal dominated interconnected system with wind integration considering Generation Rate Constraints and Governor Dead Band non linearities. Area 1 consists of two reheat thermal power generation units with wind integrated system and Area 2 comprises two non reheat thermal units. Typical values of Generation Rate Constraints (GRC) considered for non-reheat and reheat thermal units are $10 \% / \mathrm{min}$ and $3 \% / \mathrm{min}$ respectively [40,41]. Regulatory agencies like NERC [42], has specified governor deadband settings to be within $\pm 36 \mathrm{mHz}[0.06 \% \times$ nominal frequency]. Hence, a typical value of $0.06 \%$ is considered for governor dead-band non-linearity as well [43]. The governor deadband non-linearity has a destabilizing effect on the load-frequency control of a power system [43]. $K_{I 1}$ and $K_{I 2}$ are the integral gain settings in

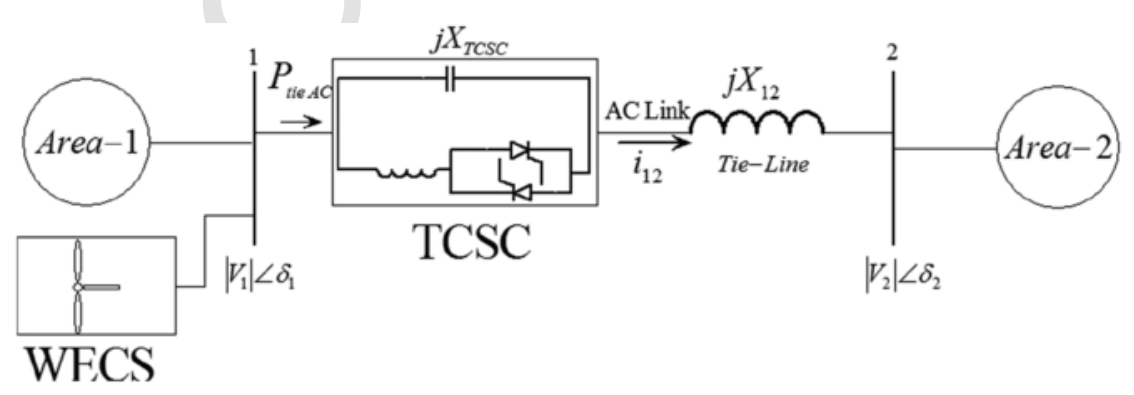

Fig. 4. Schematic model of the interconnected thermal-thermal power system with TCSC in series with the tie-line. 


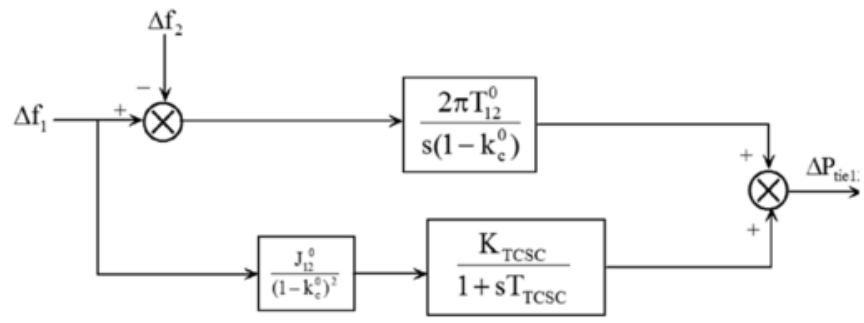

Fig. 5. Small signal model of TCSC used for AGC studies.

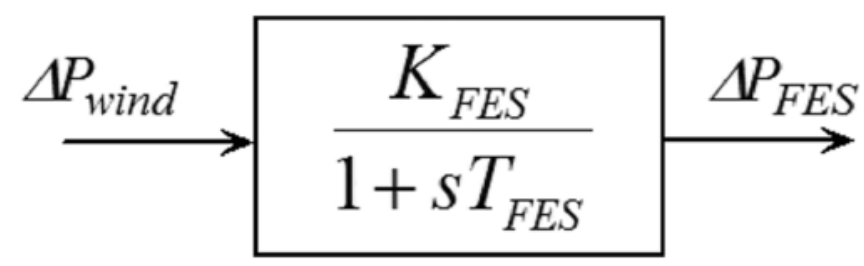

Fig. 6. Flywheel energy storage.

area 1 and area 2 respectively. The nominal parameters of the system are given in Appendix-1.

In recent years, a control area has been a mixture of conventional units such as hydro and thermal power generating units along with DFIG based wind turbines generators. On increase in the wind penetration level in the control area affects the droop settings and system inertia: equivalent droop increases whereas system inertia constant decreases. This result in the deterioration of system frequency regulation capability of the system in the absence of any frequency support from DFIG [8]. The change in system droop is given by Ref. [44]

$$
R_{n e w}=\frac{R}{\left(1-L_{P}\right)}
$$

and change in system inertia given by Ref. [44]

$$
H_{n e w}=H \times\left(1-L_{P}\right)
$$

where $L_{P}$ is the wind penetration level, ie \% reduction in the existing generating units.

\section{Particle swarm optimization}

PSO is a population based stochastic technique introduced by Kennedy and Eberhart [45]. It is modeled through simplified social model simulation inspired by bird flocking, fishing schooling and swarm theory. This optimization techniques finds application in wide variety of areas including combinatorial optimization, different types of controls including adaptive inverse, predictive or PID controls, design applications, optimization of reflect array antennas, fault tolerant power systems etc. [46]. PSO is a computational intelligence based technique that is not largely affected by the size and nonlinearity of the problem, and can converge to the optimal solution where most analytical methods fails to converge [47]. Further, easier implementation, adjustment of fewer parameters, requirement of relatively lesser memory etc are the added advantages.

PSO operates by simultaneously keeping candidate solutions in a search space. Candidate solutions are evaluated by objective functions which are being optimized to find out fitness of that solution during each iteration [47]. Candidate solutions can be initialized randomly. Particle position is the candidate solution and velocity is updated during each iteration as

$$
\begin{aligned}
v_{i}(t+1)= & w v(t)+C_{1} R_{1}\left(g_{\text {best }}-c u r\right) \\
& +C_{2} R_{2}\left(p_{\text {best }}-c u r\right)
\end{aligned}
$$

The first term in the above equation is momentum term, which signifies that its velocity cannot be changed abruptly. Second term shows cognitive thinking, i.e. contribution from its own experience while the third term highlights social behavior, collaboration among particles to choose the optimal value [48]. In a nutshell, the three main steps of PSO that occur in each iteration are

1. Evaluation of fitness of each particle

2. Updating individual and global fitness and positions

3. Updating velocity and position of each particle

A flow chart of PSO technique is given in Fig. 8. The parameters used for this analysis is tabulated in Table 1 for which there are no strict methods. Experience of the designer and the application for which PSO is being used play a crucial role in the PSO parameter selection. The computation accuracy and efficiency also depends on how the problem is being formulated.

\subsection{Optimization of integral gains using PSO}

In this work, PSO is used to optimize the integral gains. Simulations are done (a) without wind support (b) with wind support alone and (3) with wind support and FES-TCSC combination.

Automatic Generation Control maintains frequencies and tie-line power flows at scheduled values at the same time keeping settling time and overshoot as low as possible. An objective function that takes into account, the wind power generation change $\left(\Delta P_{\text {wind }}\right)$ in addition to frequency perturbations $\left(\Delta f_{1}, \Delta f_{2}\right)$ and tie-line power deviation $\left(\Delta P_{\text {tie12 }}\right)$ is formulated to tune the controller gains as given below.

$$
J=\int_{0}^{t}\left[\Delta f_{1}^{2}+\Delta f_{2}^{2}+\Delta P_{t i e 12}^{2}+\Delta P_{\text {wind }}^{2}\right] d t
$$

$\mathrm{J}$ is minimized for $1 \%$ step load perturbation in area-1 to obtain the optimum values of $K_{I 1}, K_{I 2}, K_{P}$ and $K_{I}$. The PSO parameters used for tuning are given in Table 1.

The optimal values of controller gains in the speed recovery loop of WECS obtained are used in the simulation studies. It is seen that the $K_{P}$ values deceases with wind penetration level while $K_{I}$ values increases. Also, the integral values of the control areas increase with wind penetration level. The optimized gain settings for (1) $10 \%$ wind penetration (2) $20 \%$ wind penetration and (3) $30 \%$ wind penetration for areas 1 and 2 are given in Table 2. Presented in Fig. 9 are plots showing the global best value versus iteration no. for different cases.

\section{Results and discussions}

The power system model shown in Fig. 7 is simulated using MAT$\mathrm{LAB}^{\circledR} \mathrm{R} 2013 \mathrm{~b}$ for the system data given in Appendix. A TCSC is placed near area-1 considering 50\% compensation and FES system placed near to area-2. Studies are carried out on AGC with wind penetration, for three different possibilities as given below 


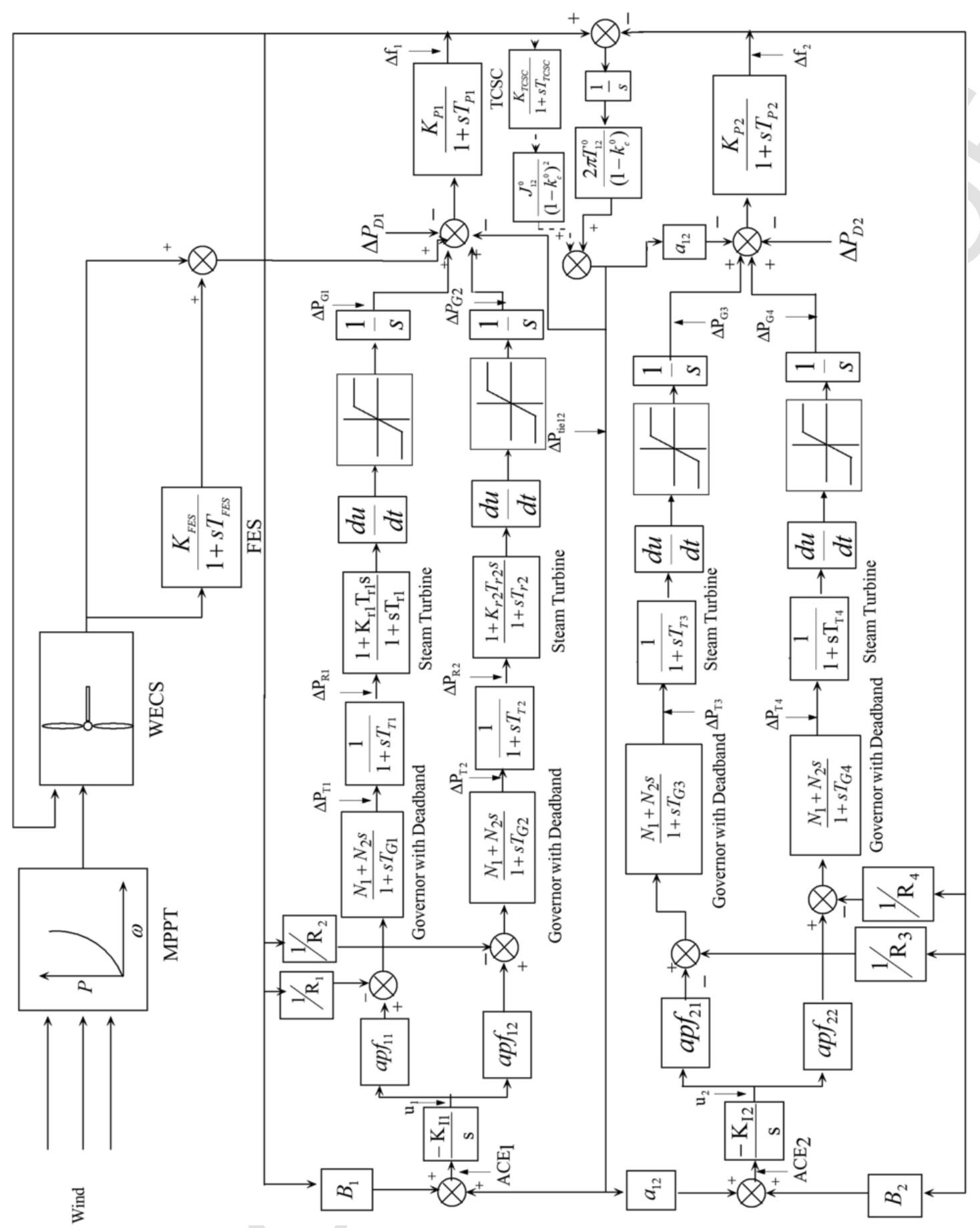

Fig. 7. Two-area thermal-thermal test system with WECS, FES and TCSC.

- Case 1: $10 \%$ wind penetration

- Case 2: $20 \%$ wind penetration

- Case 3: 30\% wind penetration

A comparison has also been done with the existing model available in Ref. [16].

\subsection{Case 1: $10 \%$ wind penetration}

The dynamic responses for the three combinations: (a) without wind support, (b) with wind support and (c) with wind support TCSC-FES are plotted in Figs. 10 and 11. With TCSC-FES combination, the transient response is improved in terms of ripples as well as settling time. Fig. 10 shows improvement in the deviations in area frequencies $\left(\Delta f_{1} \& \Delta f_{2}\right)$ and tie-line power flow $\left(\Delta P_{t i e 12}\right)$ with TCSC-FES combination in comparison with that of with wind sup- 


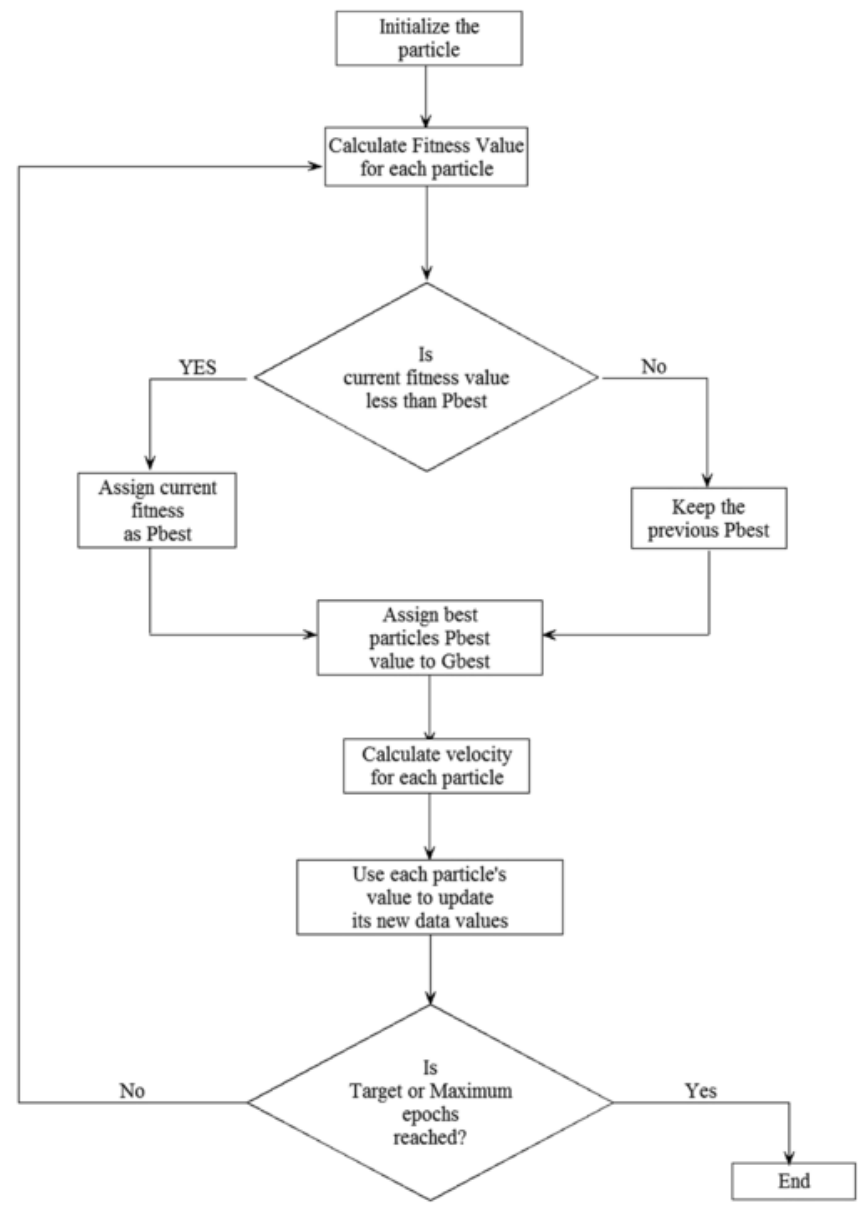

Fig. 8. PSO flow chart [48].

Table 1

PSO parameters.

\begin{tabular}{ll}
\hline No of Birds & 100 \\
Bird Step & 100 \\
PSO parameter $C_{1}$ & 1.8 \\
PSO parameter $C_{2}$ & 2.1 \\
PSO momentum or inertia w & 1.4 \\
\hline
\end{tabular}

port alone and without wind support cases. It is clear from Fig. 11 that loading in area-1 results in corresponding increase in the power generation in the thermal units of area-1. With wind integration alone, the inertia contribution from the conventional system reduces considerably, resulting in large frequency nadir. This can be reduced by providing an extra inertia support from wind turbines through in- ertia control. The TCSC-FES combination, in addition to wind support, helps to reduce this low inertia problem to a greater extent.

It is evident from Fig. 10 that during power imbalance, the system frequency deviates widely when wind turbines are not supporting primary frequency control. It establishes the well known fact that without any auxillary control like inertia control or active power control, DFIG based WTG does not take part in frequency control. It can also be observed that, with primary active power control, WTG releases the stored kinetic energy from rotor to the grid, thereby improving the frequency regulation using synthetic inertia. It is also well clear from the plots that, with TCSC-FES combination the frequency nadir point gets improved and satisfies the prevailing grid codes [42] with fast settling in a short duration of time.

At steady state, the excess load is shared between the conventional sources based on their area participation factor (-see Fig. 11(a) and (b) $\begin{array}{r}{\left[\Delta P_{D}=\Delta P_{G 1}+\Delta P_{G 2}=a p f_{11} \times 0.1\right.} \\ \left.+a p f_{12} \times 0.1=0.06+0.04=0.1\right]\end{array}$ tional power injection from wind turbines during the load disturbance in area-1. The power injection from the wind turbine reduces considerably with TCSC-FES combination due to the extra power support from FES in the event of load perturbation. Hence it can be concluded that, excess power available from the wind energy system is stored as kinetic energy in flywheels during off peak periods. At the same time in the event of load perturbation during peak hours, this stored energy in the FES is dispatched back to grid for energy balancing. This in turn enables the wind turbines to run their rotor at near optimal speed even when load disturbances occur.

The responses of thermal power plants are slower than that of wind turbines. Thermal units have longer time constants [6]. However, the Power electronic converters associated with WTG are fast switching with shorter time constant. Hence, the response of thermal power plant in Fig. 11(a) and (b) are naturally slower than wind turbine response in Fig. 11(c).

\subsection{Case 2: $20 \%$ wind penetration}

Figs. 12 and 13 depict the corresponding simulation results for the following three scenarios: (a) without wind support, (b) with wind support and (c) with wind support and TCSC-FES combination. It may be noted that with TCSC-FES, the transient oscillations and settling times have been reduced and the deviations in area frequencies $\left(\Delta f_{1} \& \Delta f_{2}\right)$ and tie-line power flow $\left(\Delta P_{\text {tie 12 }}\right)$ vanish to zero relatively faster. It is also evident that as the wind penetration level increases, the system shows more oscillatory behavior in their responses. Hence TCSC could be considered as a suitable choice to damp out these oscillations in high wind penetrated system.

Fig. 13(c) shows the extra power injected from the wind power plants during frequency excursion. With TCSC-FES combination, the change in power output of wind turbine has been reduced considerably. This is due to power support from the FES, which acts as an

Table 2

Optimum values of controller gains for $1 \%$ step load perturbation in area- 1 for various cases.

\begin{tabular}{|c|c|c|c|c|c|c|c|c|c|}
\hline \multirow[b]{2}{*}{ Wind penetration level } & \multicolumn{3}{|c|}{ Without wind support } & \multicolumn{3}{|c|}{ With wind support } & \multicolumn{3}{|c|}{ With wind support and TCSC-FES combination } \\
\hline & $10 \%$ & $20 \%$ & $30 \%$ & $10 \%$ & $20 \%$ & $30 \%$ & $10 \%$ & $20 \%$ & $30 \%$ \\
\hline \multicolumn{10}{|l|}{ Parameters } \\
\hline$K_{I 1}$ & 0.1236 & 0.1197 & 1.103 & 0.2547 & 0.2768 & 0.0969 & 0.1180 & 0.1287 & 0.1404 \\
\hline$K_{I 2}$ & 0.0200 & 0.0226 & 0.0025 & 0.0762 & 0.0852 & 0.0095 & 0.5144 & 0.5517 & 0.5886 \\
\hline$K_{P}$ & - & - & - & 0.3698 & 0.4434 & 0.4270 & 2.3235 & 1.4901 & 1.1356 \\
\hline$K_{I}$ & - & - & - & 0.0064 & 0.8260 & 0.0394 & 1.6511 & 1.8538 & 1.9807 \\
\hline
\end{tabular}




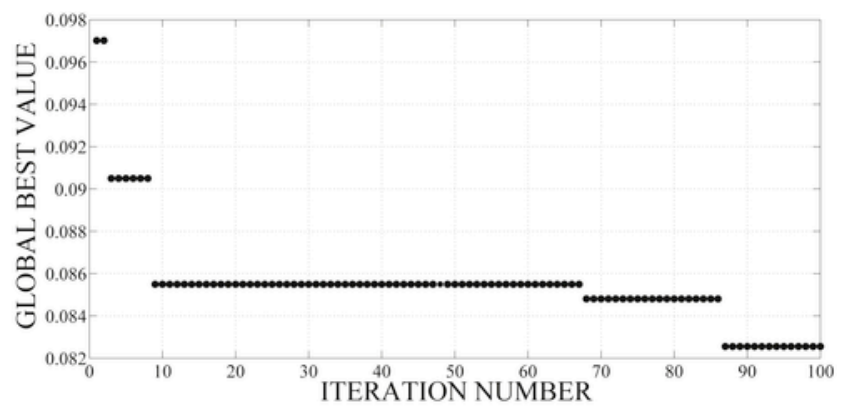

(a) Without wind support

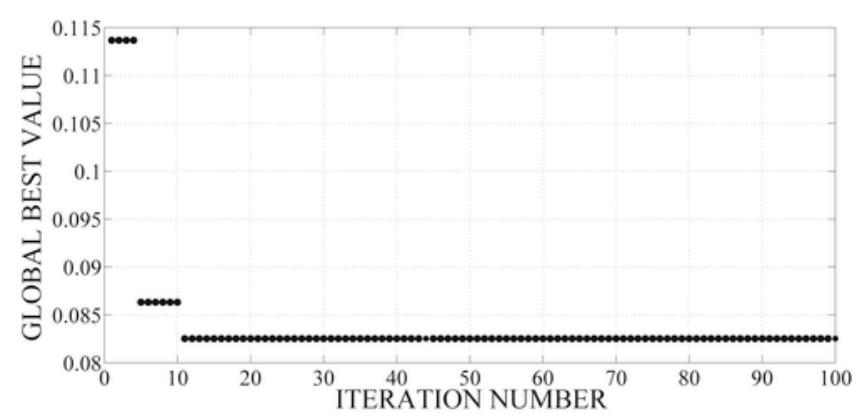

(b) With wind support

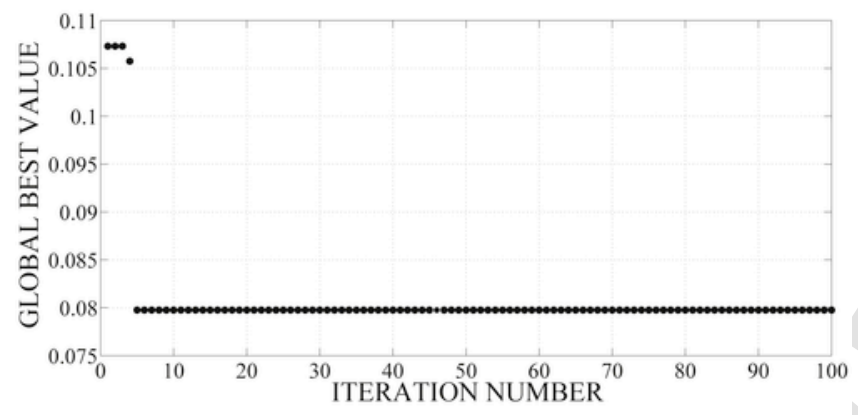

(c) With wind support and TCSC-FES

Fig. 9. Iteration vs fitness values obtained from PSO optimization for $10 \%$ wind penetration.

auxillary source. Thus it allows the rotor speed of WTG to vary over a narrow band and hence reduces the stress on WTG rotor during grid imbalances. Faster response of FES enables the grid to balance faster, thereby letting WTG release less energy as previously supplied to the grid.

\subsection{Case 3: $30 \%$ wind penetration}

In this scenario, $30 \%$ wind penetration level is considered. Figs. 14 and 15 depict the corresponding simulation results for (a) without wind support, (b) with wind support and (c) with wind support and TCSC-FES combination. It is evident from Fig. 14 that without any support from wind turbines at $30 \%$ wind penetration level, area frequencies as well as tie-line power flow, takes more time to settle down to their respective scheduled values. Further, with wind support, both frequencies and tie power settle down faster as expected. It is clear from the simulation studies that, the TCSC-FES combination along with wind support, helps to achieve better performance in terms of overshoot, settling time, damping etc. As expected, TCSC in series with tie-line provides extra damping to system to damp out low

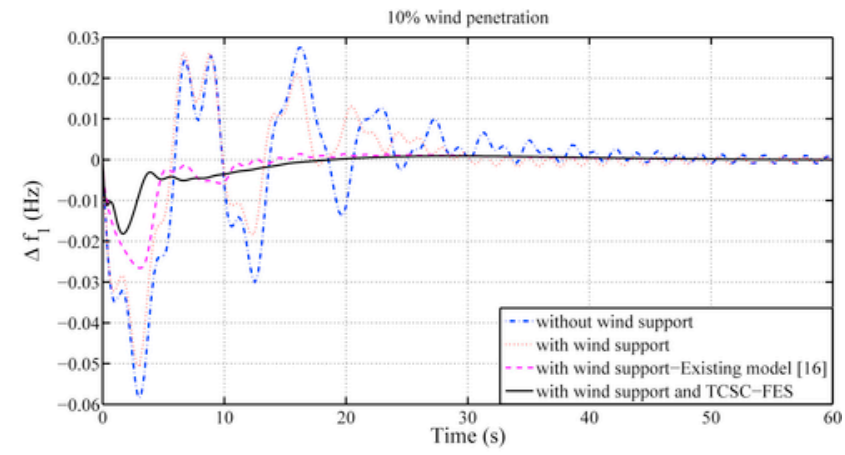

(a) Deviation in frequency of area-1

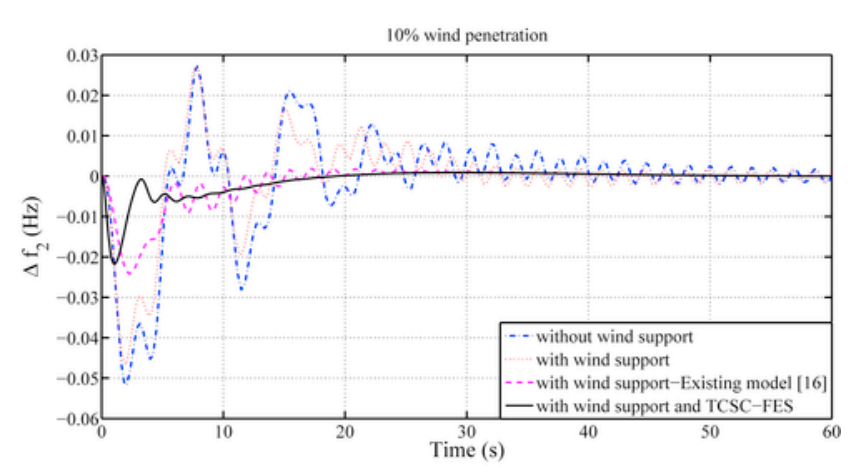

(b) Deviation in frequency of area-2

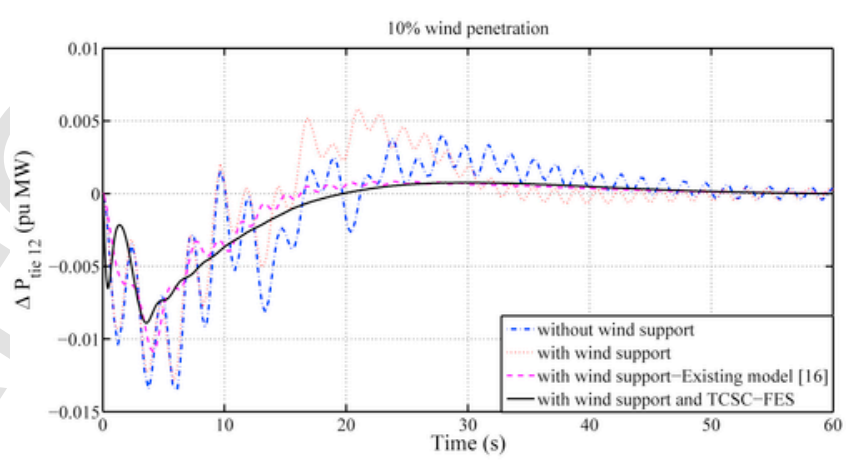

(c) Deviation in tie-line power flow

Fig. 10. Variations in area frequencies $\left(\Delta f_{1}\right.$ and $\left.\Delta f_{2}\right)$ and tie-line power $\left(\Delta P_{\text {tie12 }}\right)$ when load change in area-1 for $10 \%$ wind penetration.

frequency oscillations in both area frequencies and tie-power. FES in conjunction wind energy system provides the "frequency shaving effect" with fast responses to load demands.

Fig. 15(a)-(b) shows the deviations in power output from the generating units in area-1. As anticipated, the excess load demand is met by the thermal generating units in area-1. With the TCSC-FES combination, it is evident that, the power output from the generating units settles down to their respective values with lesser overshoot and fast settling time. Fig. 15(c) reveals that with TCSC-FES combination the extra power injected from the WTG reduces considerably in comparison with case of wind support alone.

From above results it is clear that as penetration level increases the effect of WECS is more significant whereas at low penetration levels role of TCSC-FES combination is more predominant.

Since increasing wind power penetration results in lowering the overall synchronous inertia response of the system, synthetic inertia must be provided for better system reliability. Different methods to 


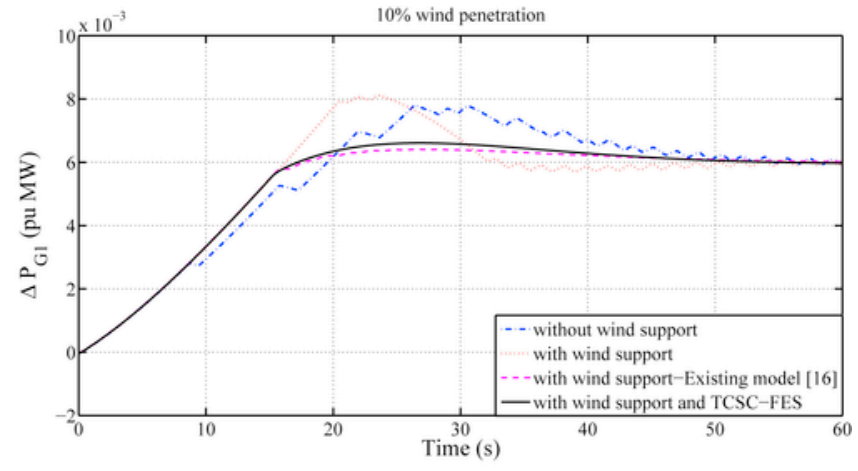

(a) Deviation in power output of reheat thermal plant-1 in area-1

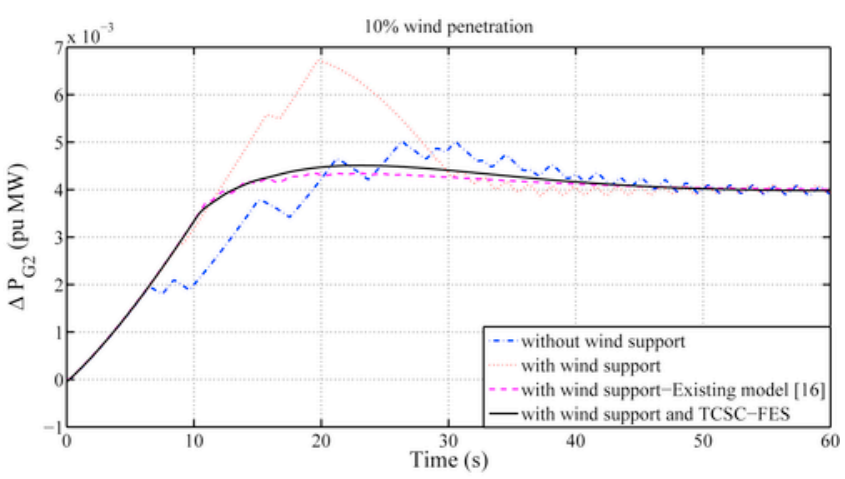

(b) Deviation in power output of reheat thermal plant-2 in area-1

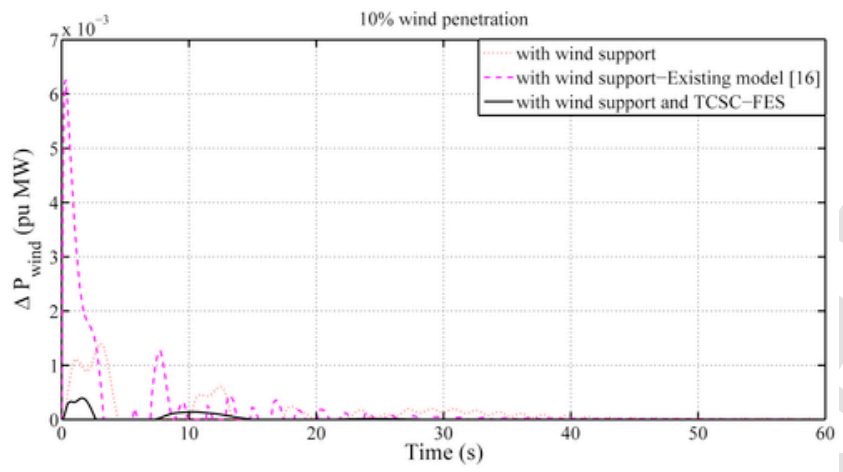

(c) Deviation in power injected from WECS

Fig. 11. Variations in power generations in area-1 $\left(\Delta P_{G 1}, \Delta P_{G 2}\right)$ and deviation in the injected wind power $\left(\Delta P_{\text {wind }}\right)$ when load change in area-1 for $10 \%$ wind penetration.

compensate for this inertia response includes various inertia emulation methods and fast acting energy storage like FES etc. to compile with the existing grid codes.

Fig. 16(a) shows deviations in power generation from wind power plant for TCSC-FES combination during grid disturbances. It is clear that, with increase in wind penetration level $(30 \%)$ the power output from WECS on primary frequency control is more in comparison with low wind penetration levels $(10 \%)$. This is due the considerable improvement in the inertia response from WECS. The power output from the FES system for TCSC-FES combination which is shown Fig. 16(b) remains more or less same at different penetration levels. As the wind penetration level increases, inertia response from WECS [equipped with inertia emulation techniques] also increases which results in the same power output from the FES system.

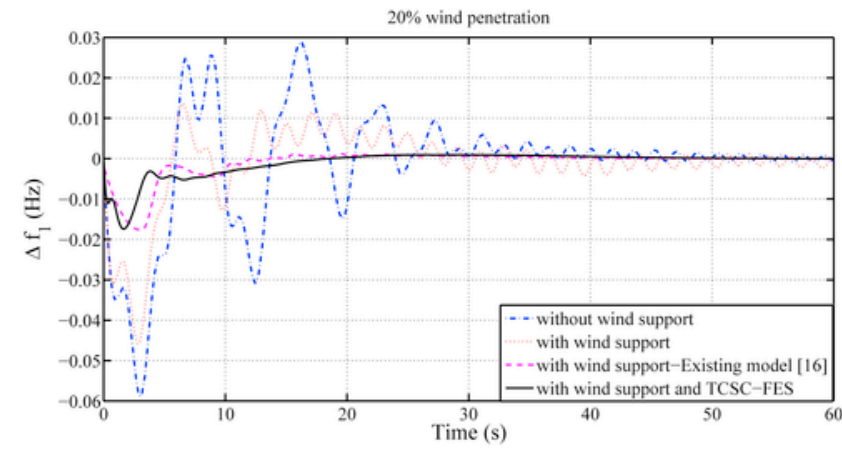

(a) Deviation in frequency of area-1

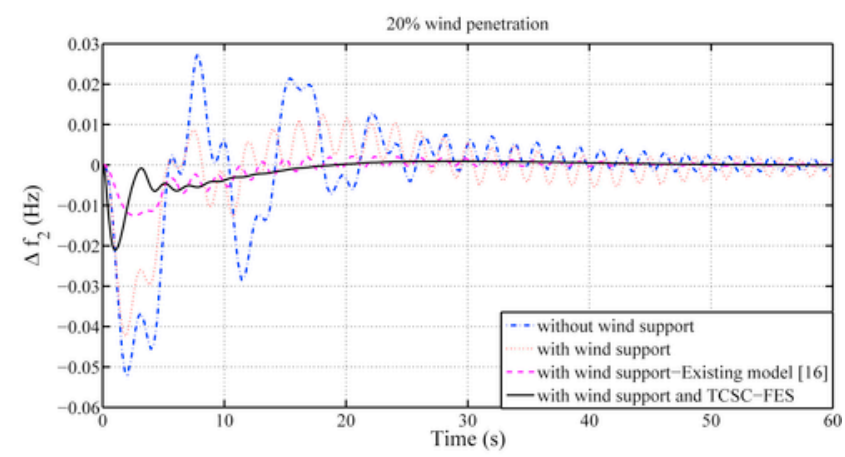

(b) Deviation in frequency of area-2

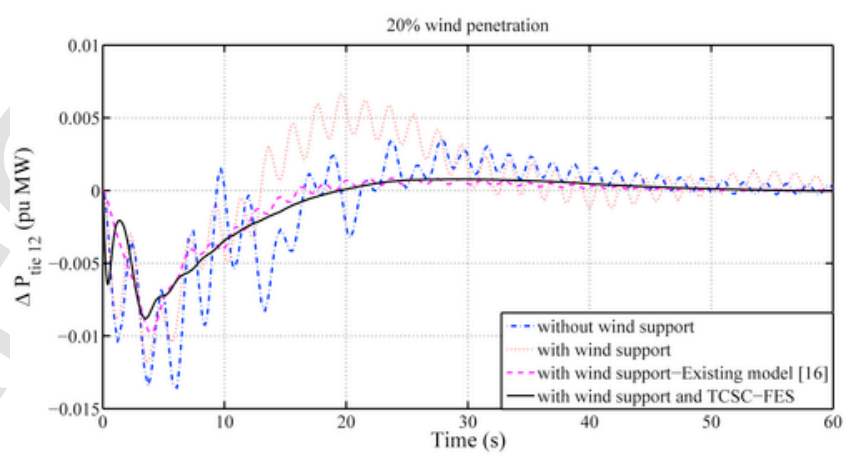

(c) Deviation in tie-line power flow

Fig. 12. Variations in area frequencies $\left(\Delta f_{1}\right.$ and $\left.\Delta f_{2}\right)$ and tie-line power $\left(\Delta P_{\text {tie12 }}\right)$ when load change in area-1 for $20 \%$ wind penetration.

A plot of variation in rotor speed versus time after $1 \%$ load perturbation with $30 \%$ wind penetration level is presented in Fig. 17. In the presence of the TCSC-FES combination, the WTG rotor speed varies over a small range even for $30 \%$ wind level penetration. It can be observed that with our proposed scheme, the rotor speed varies over a narrow band [ie., $\pm 10 \%$ of the nominal rating, which is highly desirable], which helps WTG to continuously deliver its optimal power to grid without stepping out. This establishes that, during grid imbalances FES releases stored kinetic energy to supply extra demand for short duration. Thus it allows the WTG to release less kinetic energy than it would otherwise allowing the WTGs to run close to their rated operating point. Hence FES avoids WTG stalling out from service by releasing its stored energy during large grid disturbances. 


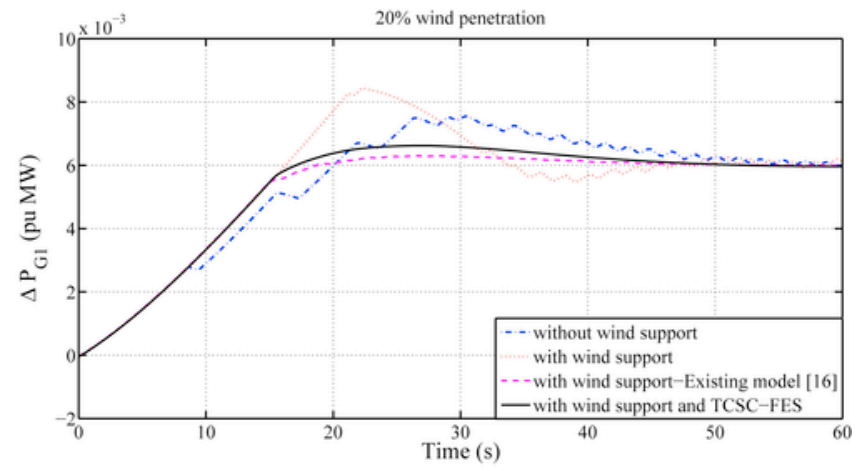

(a) Deviation in power output of reheat thermal plant-1 in area-1

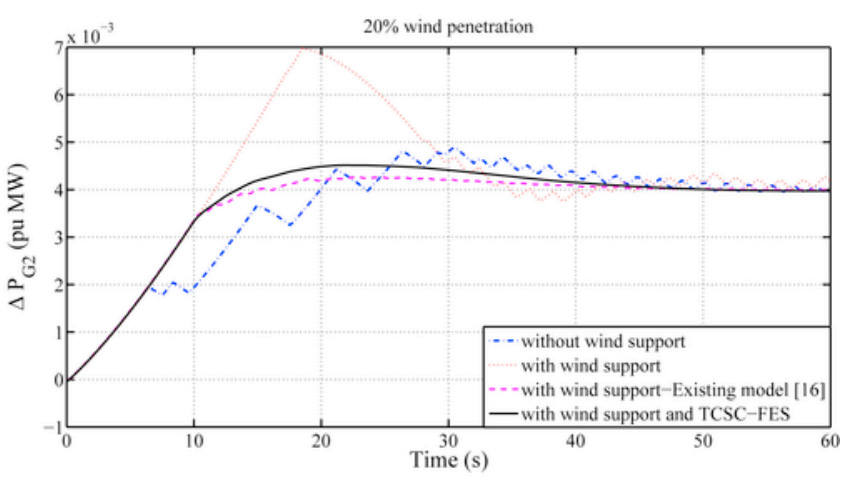

(b) Deviation in power output of reheat thermal plant-2 in area-1

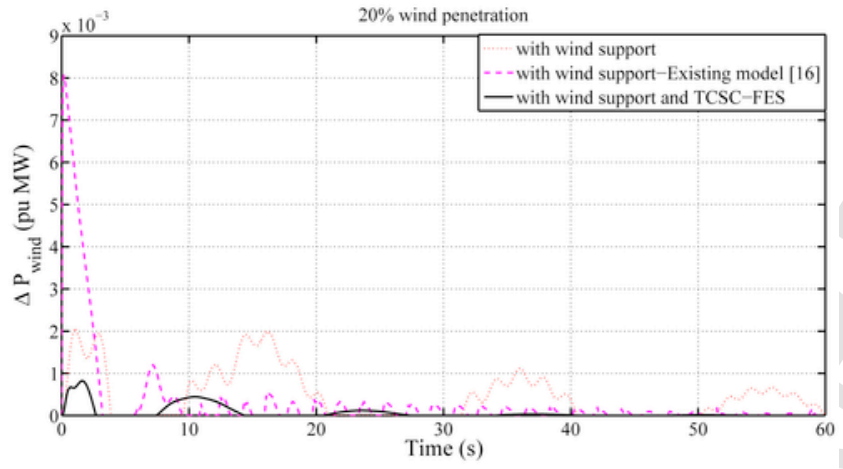

(c) Deviation in power injected from WECS

Fig. 13. Variations in power generations in area-1 $\left(\Delta P_{G 1}, \Delta P_{G 2}\right)$ and deviation in the injected wind power $\left(\Delta P_{\text {wind }}\right)$ when load change in area-1 for $20 \%$ wind penetration.

\section{Conclusion}

An attempt has been made to damp out the area frequency oscillations and tie-line power flow after a sudden load demand using TCSC-FES in an interconnected power system with wind integration. The proposed TCSC-FES combination with wind support has been used to study its effect in primary frequency support of a sample thermal dominated power system with different levels of wind penetration: $10 \%, 20 \%$ and $30 \%$ wind penetration levels. Particle Swarm Optimization has been used to tune the integral gain settings of both the areas as well as controller gains of speed recovery loop consider-

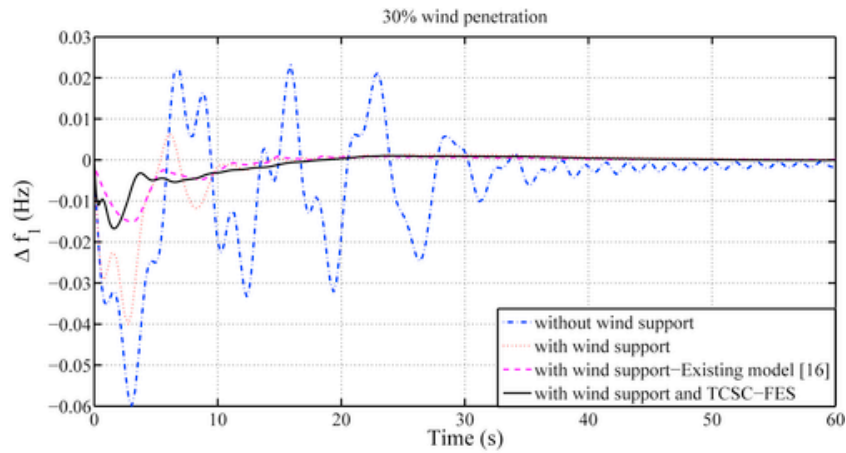

(a) Deviation in frequency of area-1

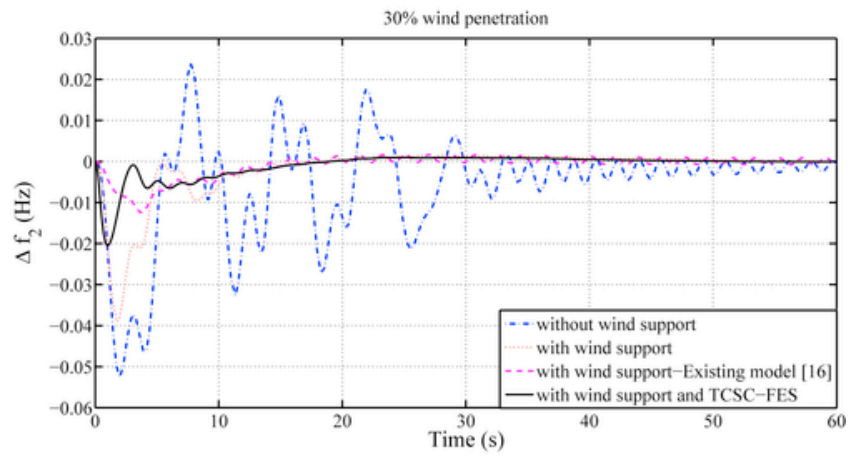

(b) Deviation in frequency of area-2

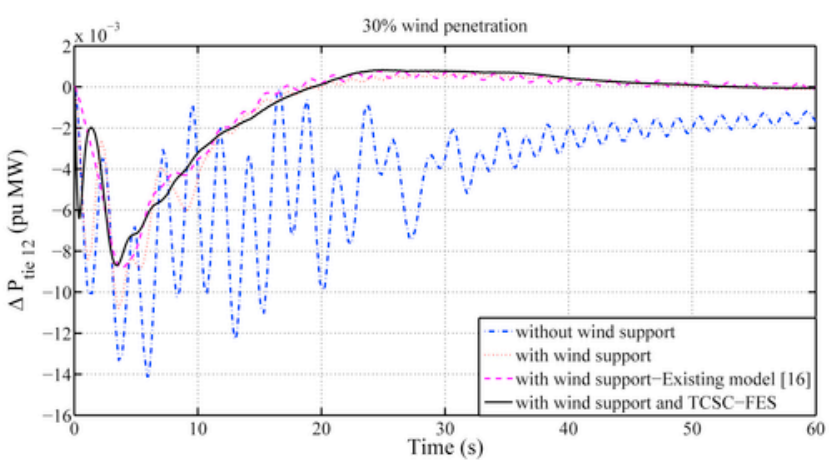

(c) Deviation in tie-line power flow

Fig. 14. Variations in area frequencies $\left(\Delta f_{1}\right.$ and $\left.\Delta f_{2}\right)$ and tie-line power $\left(\Delta P_{\text {tie12 }}\right)$ when load change in area-1 for $30 \%$ wind penetration.

ing a quadratic performance index for the above three scenarios. It is found that in all the cases, the area frequency error becomes zero at the steady state. A comparison with existing method shows that with the proposed method, dynamic responses have been improved in terms of settling time, peak overshoot, damping etc., with the use of TCSC-FES in all the three cases. Further from the analysis, it is clear that as the wind penetration level increases, the effect of WECS on primary frequency control is more while the effect of FES-TCSC is more predominant with low wind penetration levels.

\section{Appendix.}

1. System Data [27] 


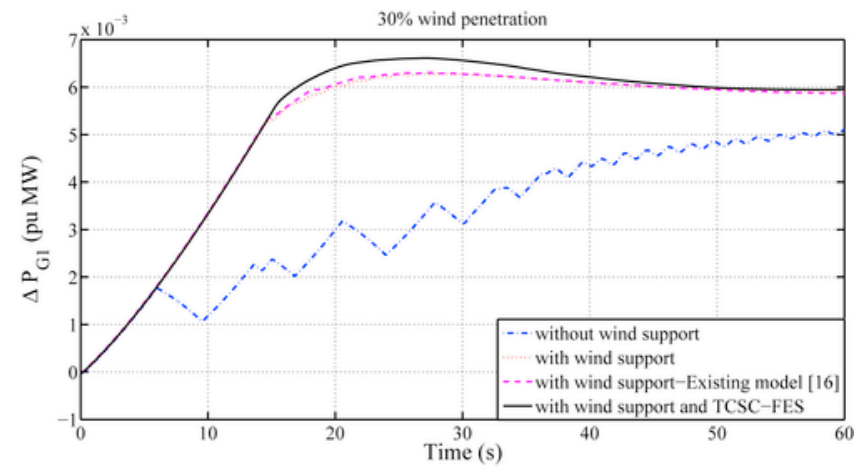

(a) Deviation in power output of reheat thermal plant-1 in area-1

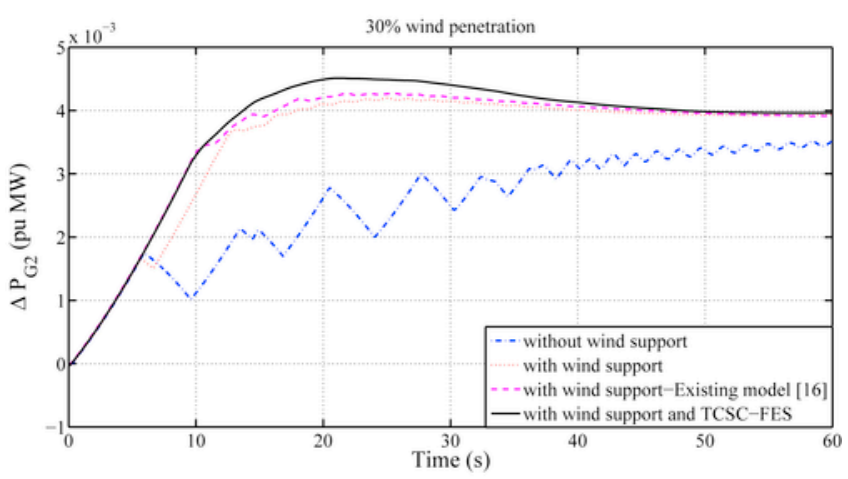

(b) Deviation in power output of reheat thermal plant-2 in area-1

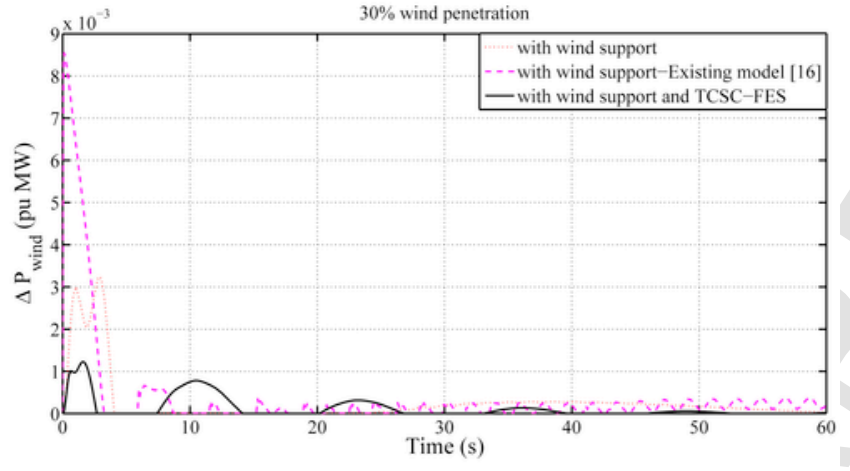

(c) Deviation in power injected from WECS

Fig. 15. Variations in power generations in area-1 $\left(\Delta P_{G 1}, \Delta P_{G 2}\right)$ and deviation in the injected wind power $\left(\Delta P_{\text {wind }}\right)$ when load change in area-1 for $30 \%$ wind penetration.

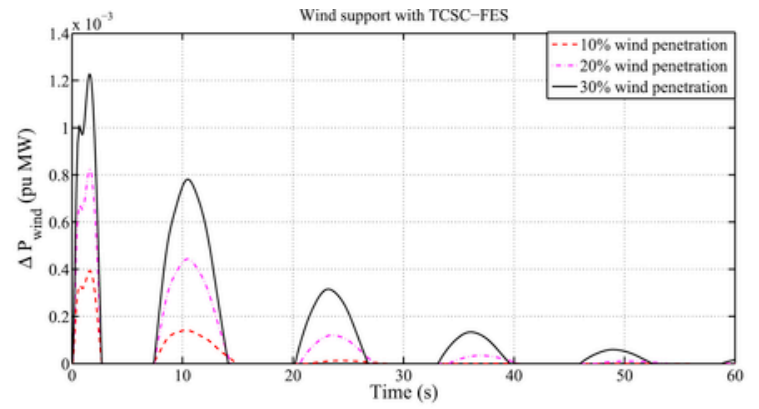

(a) Deviation in power output of wind power plant for different level of wind penetration leve

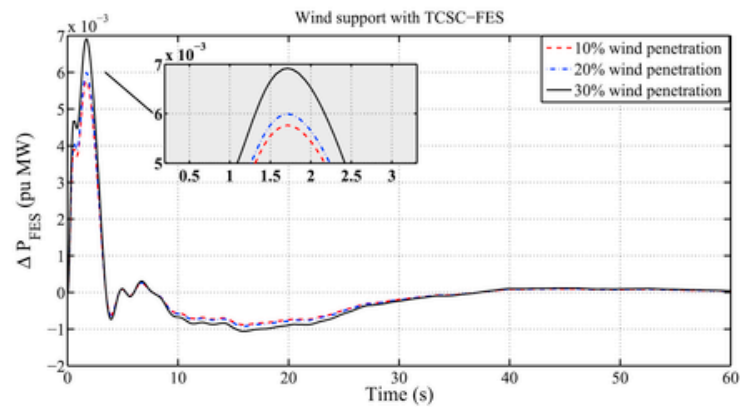

(b) Deviation in power output of FES for different level of wind penetration leve

Fig. 16. Variations in power output of wind power plant $\left(\Delta P_{\text {Wind }}\right)$ and power output of FES $\left(\Delta P_{F E S}\right)$ for different penetration levels.

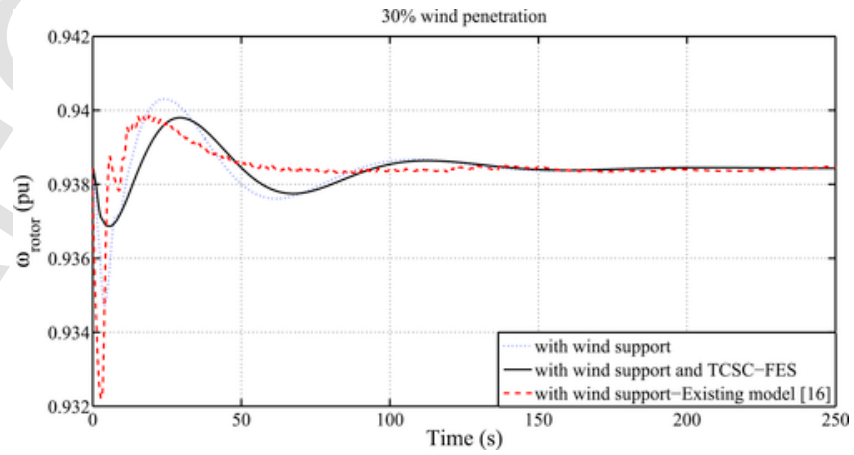

Fig. 17. WTG rotor speed variation during grid disturbance for $30 \%$ wind penetration. 


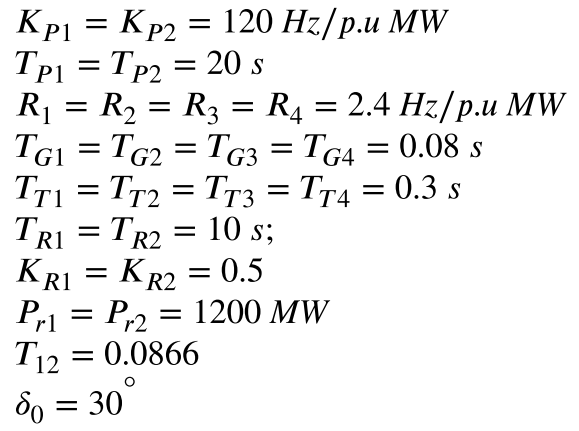

\section{TCSC Data $[49,27]$}

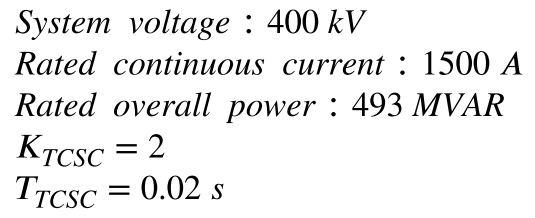

\section{Wind System [7]}

$$
\begin{aligned}
& T_{w}=6.0 \mathrm{~s} \\
& T_{R}=0.1 \mathrm{~s} \\
& T_{A}=0.2 \mathrm{~s} \\
& T_{c}=0.2 \mathrm{~s} \\
& \Delta P_{\text {windMin }} / \Delta P_{\text {windMax }}=0.0 / 1.2 \mathrm{pu} \\
& \omega_{e}^{\text {min }} / \omega_{e}^{\text {max }}=0.8 / 1.2 \mathrm{pu}
\end{aligned}
$$

\section{FES data [50-52] Nominal output rating: Up to $100 \mathrm{~kW}$} Usable energy at full charge: $200 \mathrm{kWh}$

$$
\begin{aligned}
& K_{F E S}=0.01 \\
& T_{F E S}=0.1 \mathrm{~s}
\end{aligned}
$$

[8] N. Ullah, T. Thiringer, D. Karlsson, Temporary primary frequency control support by variable speed wind turbines - potential and applications, Power Syst. IEEE Trans. 23 (2) (2008) 601-612, http://dx.doi.org/10.1109/TPWRS.2008. 920076.

[9] J. Morren, S. de Haan, W. Kling, J. Ferreira, Wind turbines emulating inertia and supporting primary frequency control, Power Syst. IEEE Trans. 21 (1) (2006) 433-434, http://dx.doi.org/10.1109/TPWRS.2005.861956.

[10] O. Anaya-Lara, F. Hughes, N. Jenkins, G. Strbac, Contribution of dfig-based wind farms to power system short-term frequency regulation, Gener. Transm. Dis. IEE Proc. 153 (2) (2006) 164-170, http://dx.doi.org/10.1049/ip-gtd: 20050264.

[11] D. Gautam, L. Goel, R. Ayyanar, V. Vittal, T. Harbour, Control strategy to mitigate the impact of reduced inertia due to doubly fed induction generators on large power systems, Power Syst. IEEE Trans. 26 (1) (2011) 214-224, http://dx. doi.org/10.1109/TPWRS.2010.2051690.

[12] L.R. Chang-Chien, W.T. Lin, Y.C. Yin, Enhancing frequency response control by dfigs in the high wind penetrated power systems, Power Syst. IEEE Trans. 26 (2) (2011) 710-718, http://dx.doi.org/10.1109/TPWRS.2010.2052402.

[13] Z. Miao, L. Fan, D. Osborn, S. Yuvarajan, Wind farms with hvde delivery in inertial response and primary frequency control, Energy Convers. IEEE Trans. 25 (4) (2010) 1171-1178, http://dx.doi.org/10.1109/TEC.2010.2060202.

[14] A. Attya, T. Hartkopf, Control and quantification of kinetic energy released by wind farms during power system frequency drops, Renew. Power Gener. IET 7 (3) (2013) 210-224, http://dx.doi.org/10.1049/iet-rpg.2012.0163.

[15] T. Taj, H. Hasanien, A. Alolah, S. Muyeen, Transient stability enhancement of a grid-connected wind farm using an adaptive neuro-fuzzy controlled-flywheel energy storage system, Renew. Power Gener. IET 9 (7) (2015) 792-800, http:// dx.doi.org/10.1049/iet-rpg.2014.0345.

[16] G. Ramtharan, J. Ekanayake, N. Jenkins, Frequency support from doubly fed induction generator wind turbines, Renew. Power Gener. IET 1 (1) (2007) 3-9, http://dx.doi.org/10.1049/iet-rpg:20060019.

[17] GE Energy WindINERTIAф Control Fact Sheet, 2009, URL: http://site. ge-energy.com/prod_serv/products/renewable_energy/en/downloads/ GEA17210.pdf.

[18] N. Miller, K. Clark, M.E. Cardinal, R.W. Delmerico, G. Energy, GE wind plant dynamic performance for grid and wind events, In: AEE TECH WIND GRID, 2009 .

[19] GE Energy, 1.5MW Wind Turbine, 2009. URL: http://geosci.uchicago.edu/ moyer/GEOS24705/Readings/GEA14954C15-MW-Broch.pdf.

[20] A. Zertek, G. Verbic, M. Pantos, A novel strategy for variable-speed wind turbines' participation in primary frequency control, Sustain. Energy IEEE Trans. 3 (4) (2012) 791-799, http://dx.doi.org/10.1109/TSTE.2012.2199773.

[21] R. Doherty, A. Mullane, G. Nolan, D. Burke, A. Bryson, M. O'Malley, An assessment of the impact of wind generation on system frequency control, Powe Syst. IEEE Trans. 25 (1) (2010) 452-460, http://dx.doi.org/10.1109/TPWRS 2009.2030348.

[22] I. Margaris, S. Papathanassiou, N. Hatziargyriou, A. Hansen, P. Sorensen, Frequency control in autonomous power systems with high wind power penetration, Sustain. Energy IEEE Trans. 3 (2) (2012) 189-199, http://dx.doi.org/10. 1109/TSTE.2011.2174660.

[23] T.H. Mohamed, J. Morel, H. Bevrani, T. Hiyama, Model predictive based load frequency control design concerning wind turbines, Int. J. Electr. Power Energy Syst. 43 (1) (2012) 859-867.

[24] P. Moutis, S.A. Papathanassiou, N.D. Hatziargyriou, Improved load-frequency control contribution of variable speed variable pitch wind generators, Renew. Energy 48 (0) (2012) 514-523

[25] K. Vidyanandan, N. Senroy, Primary frequency regulation by deloaded wind turbines using variable droop, Power Syst. IEEE Trans. 28 (2) (2013) 837-846, http://dx.doi.org/10.1109/TPWRS.2012.2208233.

[26] M. Kayikci, J. Milanovic, Dynamic contribution of dfig-based wind plants to system frequency disturbances, Power Syst. IEEE Trans. 24 (2) (2009) 859-867, http://dx.doi.org/10.1109/TPWRS.2009.2016062.

[27] M. Deepak, R.J. Abraham, Load following in a deregulated power system with thyristor controlled series compensator, Int. J. Electr. Power Energy Syst. $65(0)$ (2015) 136-145, http://dx.doi.org/10.1016/j.ijepes.2014.09.038. URL: http:// www.sciencedirect.com/science/article/pii/S0142061514005894.

[28] P. Ribeiro, B. Johnson, M. Crow, A. Arsoy, Y. Liu, Energy storage systems for advanced power applications, Proc. IEEE 89 (12) (2001) 1744-1756, http://dx. doi.org/10.1109/5.975900.

[29] A. Thatte, F. Zhang, L. Xie, Coordination of wind farms and flywheels for energy balancing and frequency regulation, In: Power and Energy Society General Meeting, 2011 IEEE, 2011, pp. 1-7, http://dx.doi.org/10.1109/PES.2011. 6039118 .

[30] Capp, F.W., Lazarewicz, M.L., Arseneaux, A.J., Dresens, P., Rojas, H.A. Methods, systems and apparatus for regulating frequency of generated power using flywheel energy storage systems with varying load and/or power generation. 2015. US Patent 9,065,295

[31] R. Yan, T.K. Saha, Frequency response estimation method for high wind penetration considering wind turbine frequency support functions, Renew. Power Gener. IET 9 (7) (2015) 775-782 
[32] M. Dreidy, H. Mokhlis, S. Mekhilef, Inertia response and frequency control techniques for renewable energy sources: a review, Renew. Sustain. Energy Rev. 69 (2017) 144-155, http://dx.doi.org/10.1016/j.rser.2016.11. 170. URL: http://www.sciencedirect.com/science/article/pii/ S1364032116309212.

[33] S. Muller, M. Deicke, R.W.D. Doncker, Doubly fed induction generator systems for wind turbines, IEEE Ind. Appl. Mag. 8 (3) (2002) 26-33, http://dx.doi.org/ $10.1109 / 2943.999610$.

[34] Y. Lei, A. Mullane, G. Lightbody, R. Yacamini, Modeling of the wind turbine with a doubly fed induction generator for grid integration studies, IEEE Trans. Energy Convers. 21 (1) (2006) 257-264, http://dx.doi.org/10.1109/TEC.2005. 847958.

[35] R. de Almeida, E. Castronuovo, J. Peas Lopes, Optimum generation control in wind parks when carrying out system operator requests, Power Syst. IEEE Trans. 21 (2) (2006) 718-725, http://dx.doi.org/10.1109/TPWRS.2005.861996.

[36] K. Clark, N.W. Miller, J.J. Sanchez-Gasca, Modeling of GE Wind Turbine-Generator for Grid Studies, Tech. Rep. Version 4.5 GE Energy; General Electric International, Inc, One River Road, Schenectady, NY 12345, USA, 2010.

[37] C. Hearn, M. Lewis, S. Pratap, R. Hebner, F. Uriarte, D. Chen, et al., Utilization of optimal control law to size grid-level flywheel energy storage, Sustain. Energy IEEE Trans. 4 (3) (2013) 611-618, http://dx.doi.org/10.1109/TSTE.2013. 2238564

[38] G.O. Cimuca, C. Saudemont, B. Robyns, M.M. Radulescu, Control and performance evaluation of a flywheel energy-storage system associated to a variable-speed wind generator, IEEE Trans. Ind. Electron. 53 (4) (2006) 1074-1085, http://dx.doi.org/10.1109/TIE.2006.878326.

[39] J.P. Barton, D.G. Infield, Energy storage and its use with intermittent renewable energy, IEEE Trans. Energy Convers. 19 (2) (2004) 441-448, http://dx.doi.org/ 10.1109/TEC.2003.822305.

[40] J. Nanda, M. Kothari, P. Satsang, Automatic generation control of an interconnected hydrothermal system in continuous and discrete modes considering generation rate constraints, Control Theory Appl. IEE Proc. D 130 (1) (1983) 17-27, http://dx.doi.org/10.1049/ip-d.1983.0004

[41] M. Kothari, P. Satsangi, J. Nanda, Sampled-data automatic generation control of interconnected reheat thermal systems considering generation rate constraints,
Power App. Syst. IEEE Trans. PAS-100 (5) (1981) 2334-2342, http://dx.doi org/10.1109/TPAS.1981.316753.

[42] S. Tripathy, G. Hope, O. Malik, Optimisation of load-frequency control parameters for power systems with reheat steam turbines and governor deadband nonlinearity, Gener. Transm. Dis. IEE Proc. C 129 (1) (1982) 10-16, http://dx.doi. org/10.1049/ip-c.1982.0002.

[43] S. Tripathy, R. Balasubramanian, P. Nair, Effect of superconducting magnetic energy storage on automatic generation control considering governor deadband and boiler dynamics, Power Syst. IEEE Trans. 7 (3) (1992) 1266-1273, http:// dx.doi.org/10.1109/59.207343.

[44] P. Bhatt, S. Ghoshal, R. Roy, Coordinated control of TCPS and SMES for frequency regulation of interconnected restructured power systems with dynamic participation from DFIG based wind farm, Renew. Energy 40 (1) (2012) 40-50.

[45] K.T. Chaturvedi, M. Pandit, L. Srivastava, Self-organizing hierarchical particle swarm optimization for nonconvex economic dispatch, Power Syst. IEEE Trans. 23 (3) (2008) 1079-1087.

[46] R. Poli, Analysis of the publications on the applications of particle swarm optimisation, J. Artif. Evol. Appl. 10 (2008) http://dx.doi.org/10.1155/2008/685175.

[47] Y. Del Valle, G.K. Venayagamoorthy, S. Mohagheghi, J.C. Hernandez, R.G Harley, Particle swarm optimization: basic concepts, variants and applications in power systems, IEEE Trans. Evol. Comput. 12 (2) (2008) 171-195.

[48] R.C. Eberhart, Y. Shi, Comparing inertia weights and constriction factors in particle swarm optimization, Evol. Comput. Proc. 2000 Congr. 1 (2000) 84-88.

[49] ABB, TCSC Thyristor Controlled Series Compensation Keeping Grids Together, 2016. URL: https:/library.e.abb.com/public/ fdf0b019e1fe08a48325771f002dbfc5/A02-0158.pdf

[50] G. Thijssen, J. Enslin, Cost Comparison for a 20 MW Flywheel-based Frequency Regulation Power Plant, KEMA-Inc Project: BPCC 20073.

[51] I. Pan, S. Das, Fractional order AGC for distributed energy resources using robust optimization, Smart Grid IEEE Trans. PP (99) (2015) http://dx.doi.org/10 1109/TSG.2015.2459766. 1-1.

[52] R. Rounds, G. Peek, Design \& Development of a 20-mw Flywheel-based Frequency Regulation Power Plant, 2008. 